\title{
冷凍食品に分布する腸球菌の種類
}

\author{
(昭和 51 年 9 月 24 日受理)
}

堀江 進* 安藤広志* 阿部正明*

\section{Distribution of Enterococcal Species in Commercial Frozen Foods}

\author{
Susumu HoRIE, Hiroshi ANDo and Masaaki ABE
}

(Tokyo University of Fisheries: 5-7, Konan 4-chome, Minato-ku, Tokyo)

\begin{abstract}
Enumeration and isolation of enterococci in 72 samples of commercial frozen foods were carried out by using AE (Azide Esculin) agar plates. Among 561 strains which isolated from 61 samples, 447 strains from 58 samples were identified with enterococci by the completed test: gram positive cocci, negative catalase test, growth in $6.5 \%$ Sodium chloride glucose broth, and final $\mathrm{pH}$ in glucose broth between 4.0 and 4.4. These enterococcal isolates were divided into the species according to the "MSAG" tests, fermentation of mannitol, sorbitol and arabinoșe, and liquefaction of gelatine. Ninty five strains (21.3\%) of Streptococcus faecalis were recovered from 32 samples, $102(22.8 \%)$ of $S$. faecalis subsp. liquefaciens from 32 samples, $212(47.4 \%)$ of $S$. faecium from 40 samples, $15(3.4 \%)$ of $S$. durans from 7 samples, $23(5.1 \%)$ of atypical forms were isolated from 14 samples. In order to investigate the result of identification tests mentioned above, 133 of the enterococcal isolates were examined by the 6 additional tests: fermentation of glycerol, melezitose and melibiose, nutritional requirement of folic acid, reduction of triphenyltetrazolium chloride, and resistance to $0.04 \%$ potassium tellurite. The results showed that most of the enterococcal species which had been primarily determined by the "MSAG" tests were approved after the additional 6 tests.
\end{abstract}

(Received September 24, 1976)

腸球菌は食品の凍結ならびに冷凍䝪蔵中にほとんど死 隇しない点で, 冷凍食品の污染指標として優れている. またその検査法もほぼ確立し，実用の域に達しているも のと考えられる. 冷凍食品における大腸菌群之腸球菌の

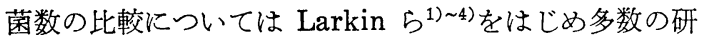
究があり, 堀江ら ${ }^{5}$ も近年これに関し報告している.し かし冷凍食品に含まれる腸球菌の種類についての検討は 少ない。

Kereluk ら ${ }^{6)}$ は市販の冷凍肉パイの腸球菌分離菌株を 調ベ，その大部分は Streptococcus faecalis および $S$. faecalis var. liquefaciens によって占められ，S. faecium は少数であったと報告している. Raj らは冷凍 水産食品から分離された腸球菌株を調べたところ， $S$. faecalis var. liquefaciens が多数を占め, S. durans がこれにつぎ, S. faecium は極めて少数であったと述 べている.ささて,これらの腸球菌の測定あるいは分離に

* 東京水産大学: 東京都港区港南 4-5-7
は Difco Manual ${ }^{8)}$ に記載のある “Azide Dextrose Broth" (AD) と Litsky ら")の “Ethyl Violet Azide" (EVA) 培地を組み合わせた $\mathrm{AD}$-EVA 法, すなわち, 液体培地が用いられている関係から，腸球菌フローラを 形成する菌種の割合を明確に示すものとはいい難い，今 回著者らは AE 寒天平板培地 ${ }^{10)}$ を用いて市販冷凍食品 の腸球菌を測定し，その集落を釣菌し，腸球菌フローラ を形成する菌種について観察を試みた。

\section{実験方法}

\section{冷凍食品検体}

東京都内および横浜市内の百貨店において 1973 年 12 月から 1974 年 11 月の間, 72 検体を購入し実験に供し た。

\section{腸球菌の測定}

検体の容器包装の表面を $70 \%$ アルコール綿でぬぐ い, その $25 \mathrm{~g}$ を隇菌したホモジナイザーに採取し，隇 菌リン酸緩衝食塩水 ${ }^{11)} 225 \mathrm{ml}$ を加え 2 分間細砕したも のを 10 倍希勫液とし，さらに常法により 100 倍希釈液 
Table 1. The Differential Characters of Enterococci Applied in the Present Study

\begin{tabular}{|c|c|c|c|c|c|}
\hline & & $\begin{array}{l}\text { Streptococcus } \\
\text { faecalis }\end{array}$ & $\begin{array}{l}\text { S. faecalis subsp. } \\
\text { liquefaciens }\end{array}$ & S. faecium & S. durans \\
\hline \multirow{3}{*}{ Acid from } & (Mannitol & + & + & + & - \\
\hline & $\{$ Sorbitol & + & + & - & - \\
\hline & Arabinose & - & - & + & - \\
\hline \multicolumn{2}{|c|}{ Liquefaction of gelatine } & - & + & - & - \\
\hline \multirow{3}{*}{ Acid from } & (Glycerol & + & + & - & - \\
\hline & $\{$ Melezitose & + & + & - & - \\
\hline & Melibiose & - & - & + & + \\
\hline \multicolumn{2}{|c|}{ Requirement of folic acid } & - & - & + & + \\
\hline \multicolumn{2}{|c|}{ Reduction of tetrazolium } & + & + & - & - \\
\hline \multicolumn{2}{|c|}{ Resistance to $0.04 \%$ tellurite } & + & + & - & - \\
\hline
\end{tabular}

を得た. 10 倍希釈液 $1 \mathrm{ml}$ を $\mathrm{AE}$ 寒天培地に混合し, また 10 倍および 100 倍希釈液の $0.1 \mathrm{ml}$ を $\mathrm{AE}$ 平板 培地の表面に塗抹し，いずれも $45^{\circ}$ で 24 時間培養し た. その結果，黑色の “Halo”を有する定型的な集落を 数乥て推定腸球菌数を求めた.なお各段階 2 枚ずつの平 板培地を用い平均值を出した。

\section{腸球菌菌株の分離}

1 検体当たり，腸球菌の定型的集落と認められるもの 10 個（またはそれ以下）を釣菌し，堀江ら ${ }^{10)}$ 方法に より完全試験を行った.

"MSAG" (Mannitol, Sorbitol, Arabinose, Gelatine) 試験による菌種の同定

完全試験陽性の全菌株について，マンニット，ソルビ ット，アラビノース分解ならびにゼラチン液化の 4 項目 試験を行いTable 1 により同定した。

\section{生物学的性状の試験法}

菌種の同定に必要な下記の性状試験を行った，培養試 験において, 特記しない限り培養温度は $37^{\circ}$ とし, ブド ウ糖ブイヨン (ポリペプトン $10 \mathrm{~g}$, 肉エキス $5 \mathrm{~g}$, ブド ウ糖 $10 \mathrm{~g}$, 塩化ナトリウム $5 \mathrm{~g}$, 蒸留水 $1,000 \mathrm{ml}, \mathrm{pH}$ 7.0)に 24 時間培養したものを接種菌とした。

$6.5 \%$ 食塩加ブドウ糖ブイヨンにおける增殖： $6.5 \%$ 食塩加ブドウ糖ブイヨン (ポリペプトン $10 \mathrm{~g}$, 肉エキス $5 \mathrm{~g}$, ブドウ糖 $10 \mathrm{~g}$, 塩化ナトリウム $65 \mathrm{~g}$, 蒸留水 1,000 $\mathrm{ml}, \mathrm{pH}$ 7.0)を用いた。

終末 $\mathrm{pH}$ の測定：前記ブドウ糖ブイヨンに 4 日間培養 後 BCG（ブロムクレジールグリーン）試験紙で $\mathrm{pH}$ が 4.0 4.4 であるか否かを試験した.

炭水化物分解試験：炭水化物分解試験用培地（ポリペ プトン $10 \mathrm{~g}$ ，酵母エキス $3 \mathrm{~g}$ ，塩化ナトリウム $5 \mathrm{~g} ， \mathrm{BTB}$ (ブロムチモールブルー) $0.024 \mathrm{~g}$, 炭水化物 $10 \mathrm{~g}$, 蒸留

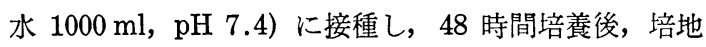
の黄変により酸の生成を観察した.

ゼラチン液化試験：Deibel ら ${ }^{12)}$ の培地を改変した培
地（バクトトリプトン $10 \mathrm{~g}$ ，醅母エキス $5 \mathrm{~g}$ ，リン酸二 カリウム $5 \mathrm{~g}$, 塩化ナトリウム $5 \mathrm{~g}$, ブドウ糖 $0.5 \mathrm{~g}$, ゼ ラチン $150 \mathrm{~g}$, 蒸留水 $1,000 \mathrm{ml}, \mathrm{pH} 7.0)$ を用い, $37^{\circ}$ 7 日間培養後，冷却し，凝固の有無を観察した。

TTC（トリフェニルテトラゾリウムクロライド）還元 試験: Barnes ${ }^{13}$ の の TG 培地を一部改変した培地（バク トペプトン $10 \mathrm{~g}$, 極東牛肉エキス $10 \mathrm{~g}$, 塩化ナトリウ ム $5 \mathrm{~g}$, ブドウ糖 $10 \mathrm{~g}$, TTC $0.075 \mathrm{~g}$, 蒸留水 $1,000 \mathrm{ml}$, $\mathrm{pH}$ 6.0 6.1) を用いた。培地を調製するには，ペプト ン $1 \mathrm{~g}$, 牛肉エキス $1 \mathrm{~g}$, 塩化ナトリウム $0.5 \mathrm{~g}$ を $95 \mathrm{ml}$ の蒸留水に溶解し， $121^{\circ} ， 15$ 分間隇菌した。これに $115^{\circ}, 10$ 分間隇菌した $20 \%$ ブドウ糖溶液 $5 \mathrm{ml}, 100^{\circ}$, 30 分間隇菌した TTC $1 \%$ 溶液 $0.75 \mathrm{ml}$ をそれぞれ無 菌的に加え, 中試験管に $5 \mathrm{ml}$ ずつ無菌的に分注した。 減菌ピペットで菌液の 1 滴を本培地に接種し， 24 時間 培養後ブタノール $5 \mathrm{ml}$ を加え, 振とう後静置した.ブ タノール層が赤色を呈した場合を陽性とした。

$0.04 \%$ 亜テルル酸カリウム抵抗性試験： 橋本 ${ }^{14)}$ の記 載した培地を用い，4 日間培養し, 増殖の有無を観察し た.

葉酸要求試験：日水製薬(株)製の葉酸定量用培地を用 いた。これに葉酸 $10 \mu \mathrm{g} / 1000 \mathrm{ml}$ 加えたものを基礎培地 とした。これらの培地は小試験管に $2.5 \mathrm{ml}$ ずつ分注し, $121^{\circ} ， 5$ 分間減菌して用いた。 まず基礎培地に接種し, 24 時間培善し, 增殖したものを径 $0.3 \mathrm{~mm}$ の白金線を 用い，同基礎培地ならびに葉酸定量用培地に接種し， 24 〜 48 時間培養し，增殖の有無を比較した。

$\beta$ 溶血性試験: “Blood Agar Base” (Difco)を用い, これにウマの脱線維素血液を $5 \%$ 量加えて調製した血 液寒天を用いた。

\section{実験結果と考察}

\section{推定腸球菌数の測定と完全試験}

実験結果は Table 2 に示すとおりである. 冷凍食品 72 検体において推定腸球菌数は $1 \mathrm{~g}$ 当たり，<10が 12 
Table 2. Enumeration of Enterococci in the Frozen Foods and Identification of the Isolates by "MSAG" Reactions*1

\begin{tabular}{|c|c|c|c|c|c|c|c|c|c|c|c|c|c|c|c|c|}
\hline \multirow[b]{3}{*}{ Frozen foods } & \multirow{3}{*}{ 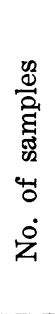 } & \multicolumn{6}{|c|}{$\begin{array}{l}\text { Presumptive enterococcal } \\
\text { counts } \mathrm{g}^{* 2}\end{array}$} & \multicolumn{2}{|c|}{$\begin{array}{l}\text { Completed } \\
\text { test }\end{array}$} & \multicolumn{7}{|c|}{ MSAG reactions } \\
\hline & & \multirow[b]{2}{*}{$\begin{array}{l}0 \\
\frac{3}{3} \\
\frac{0}{0} \\
\infty\end{array}$} & \multirow[b]{2}{*}{ 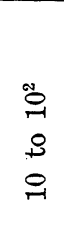 } & \multirow[b]{2}{*}{ 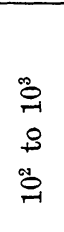 } & \multirow[b]{2}{*}{$\begin{array}{l}\ddot{0} \\
\stackrel{1}{0} \\
8 \\
8 \\
0 \\
0\end{array}$} & \multirow[b]{2}{*}{$\begin{array}{l}\infty \\
0 \\
0 \\
8 \\
+0 \\
0 \\
0\end{array}$} & \multirow[b]{2}{*}{$\begin{array}{l}: \\
0 \\
\vdots \\
0 \\
0 \\
0\end{array}$} & \multirow[b]{2}{*}{ 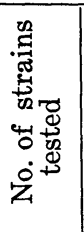 } & \multirow[b]{2}{*}{ 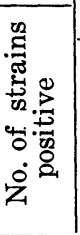 } & \multicolumn{4}{|c|}{ Typical } & \multicolumn{3}{|c|}{ Atypical } \\
\hline & & & & & & & & & & 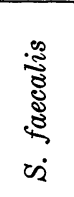 & 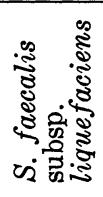 & 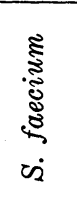 & 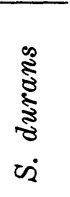 & $\begin{array}{l}- \\
- \\
+ \\
-\end{array}$ & $\begin{array}{l}+ \\
+ \\
+ \\
-\end{array}$ & $\begin{array}{l}+ \\
- \\
- \\
-\end{array}$ \\
\hline Shrimp & 10 & & $3^{* 3}$ & 34 & 3 & & & 91 & 60 & 18 & 19 & 19 & 2 & & 2 & \\
\hline Peeled & 7 & & 1 & 3 & 3 & & & 70 & 47 & 17 & 16 & 9 & 3 & & 2 & \\
\hline Breaded shrimp & 16 & 2 & 5 & 5 & 2 & 1 & 1 & 132 & 104 & 27 & 31 & 42 & 1 & 3 & & \\
\hline Croquette & 14 & 2 & 3 & 6 & 1 & 2 & & 117 & 107 & 13 & 12 & 72 & 1 & 7 & & 2 \\
\hline Breaded fish & 8 & & 2 & 4 & 1 & 1 & & 73 & 65 & 12 & 11 & 32 & 8 & 1 & 1 & \\
\hline Breaded oyster & 4 & 2 & 2 & & & & & 14 & 7 & & & 5 & & & 1 & 1 \\
\hline Miscellaneous & 13 & 6 & 2 & 2 & 3 & & & 64 & 57 & 8 & 13 & 33 & & 2 & & 1 \\
\hline 10tal & 72 & 12 & 18 & 24 & 13 & 4 & 1 & 561 & $\begin{array}{l}447 \\
100^{* 4}\end{array}$ & $\begin{array}{c}95 \\
21.3\end{array}$ & $\begin{array}{l}102 \\
22.8\end{array}$ & $\begin{array}{l}212 \\
47.4\end{array}$ & $\begin{array}{l}15 \\
3.4\end{array}$ & $\begin{array}{r}13 \\
2.9\end{array}$ & $\begin{array}{r}6 \\
1.3\end{array}$ & $\begin{array}{r}4 \\
0.9\end{array}$ \\
\hline
\end{tabular}

*1 Fermentation of mannitol, sorbitol, and arabinose, and liquefaction of gelatine

*2 Determined by AE agar plate counts

*3 Figures represent numbers of samples

$* 4 \%$

検体, $10 \sim 10^{2}$ が 18 検体, $10^{2} \sim 10^{3}$ が 24 検体, $10^{3} \sim 10^{4}$ が 13 検体, $10^{4} \sim 10^{5}$ が 4 検体, >10 72 検体の中の 61 検体から 561 菌株を分離したが，その中 で完全試験の結果腸球菌に同定されたものは58検体から の 447 株 (79.7\%) であった。すなわち $\mathrm{AE}$ 培地上の定 型的集落の約 $80 \%$ は腸球菌に同定された.

\section{“MSAG”試験による菌種の同定}

腸球菌に同定された 447 株についてマンニット，ソル ビット，アラビノース，ゼラチンの 4 項目試験の結果に より第一次的に菌種の同定を行った成績を Table 2 に示 した. S. faecium が 212 株 (47.4\%) で最も多く, 40 検体から分離されており, S. faecalis subsp. liquefaciens が 102 株 (22.8\%), S. faecalis が 95 株 (21.3\%) でこれにつぎ，いずれも 32 検体から分離され，これら の菌種で $91.5 \%$ を占めた. そして S. durans は 7 検 体から得られた 15 株（3.4\%）にすぎなかった。 また非 定型菌株は 14 検体から分離された 23 株 $(5.1 \%)$ であ った．また冷凍食品の種類別にみると，エビおよびむき 身エビではS. faecium の比率が比較的低く, これと反 対にフライ類, 特にコロッケ類では S. faecium が圧倒 的に多数を占めている点が目立っている.

\section{“MSAG”試験による同定成績に対する検討}

前述のように“MSAG” 試験により全菌株についての 菌種の鑑別を試みたわけであるが，さらに正確な菌種の： 同定を行うには Table 1 に示した他の 6 項目の試験が
必要であると考える，そこで Table 2 に示した同定成 績を吟味する目的で, “MSAG”試験で定型的性状を示 した菌株の中から無作為に 120 株を選び，また非定型的 性状の菌株の中から無作為に 13 株を選び，合計 133 株 について上記 6 項目の試験を行い, 結局 10 項目の試験 結果によって再検討した. Table 1 には鑑別特性として 10 項目を挙げたが, その各菌種の典型的特性の中で 8 項目以上を有するものをその菌種に同定することとし た。なおこの他 $\beta$ 溶血試験も行ったが全菌株が陰性で あった．実験結果を Table 3 に示した. “MSAG”にお いて++ーーを示し，S. faecalis に同定された 24 株 についてみると，その中の 19 株は典型的性状を示し， また他の 4 株も 8 項目以上の特性を有するので S. faecalis に同定され，1株のみが非定型株とされた。なお， “MSAG”で +ーーーを示し非定型とされていた 1 株 が 10 項目の結果では S. faecalis に同定された．次に “MSAG”で ++-+の 27 株についてみると, 24 株 は典型的性状を示し，他の 3 株を含めてすべて S. faecalis subsp. liquefaciens に同定された. “MSAG”で +ー+ー，すなわち S. faecium に同定された 61 株に ついて 10 項目試験の結果をみると, 53 株は S. faecium に同定され，その中 41 株が典型的性状を示した。 そし て8株が非定型株とされた。これらの菌株は TTC 還元 ならびに亜テルル酸塩抵抗性がいずれも陽性である点が 注目される。この他 “MSAG”試験では非定型に入れら 
Table 3. Results of 10 Biochemical Tests Made for the Identification of 133 Enterococcal Isolates

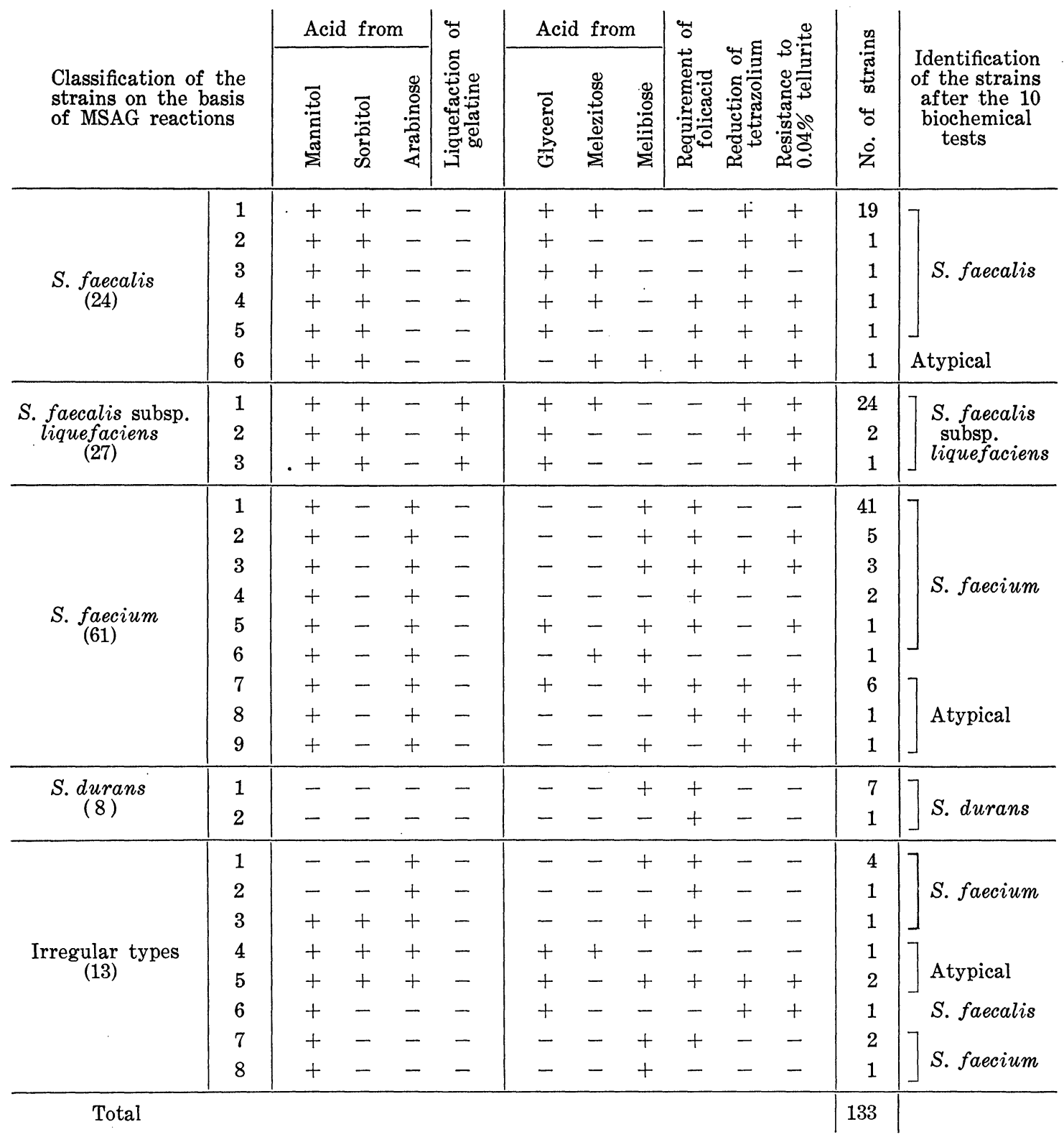

れたマンニット陰性の 5 株, アラビノース陰性の 3 株, ソルビット陽性の 1 株などが 10 項目試験の結果では $S$. faecium に同定された. “MSAG”で S. durans に同定 された 8 株は 10 項目試験の結果でもすべて S. durans に同定された.

以上の成績によると“MSAG” 試験で S. faecalis, S. faecalis subsp. liquefaciens および S. duransに 同定された菌株のほとんどすべては 10 項目試験の結果 においても変動がなかった。すなわち，これらの菌種に
ついては “MSAG”による同定試験の正確性が高いよう である。これに対し，“MSAG”で S. faecium に同定 された菌株においては 10 項目の結果, 非定型株とされ たものが若干あり，また逆に“MSAG”で非定型株とさ れたものが，10 項目の結果では S. faecium に同定さ れた例もかなりあった。

本研究の成績によると市販冷凍食品の腸球菌フローラ シにおいては，そのほとんぞが S. faecium ならびに S. faecalis (S. faecalis subsp. liquefaciens を含む) に 
よって占められており，S.durans は少なく，また同定 困難な菌株の少ないことを知った。

\section{要 約}

市販冷凍食品の 72 検体について, AE (アザイド・エ スクリン) 寒天平板培地を用いて, 推定腸球菌数を測定

し, またその中の 58 検体から腸球菌 447 株を分離し得 た。これらを “MSAG”試験（マンニット,ソルビット， アラビノースの発酵, ゼラチン液化）により同定したと ころ, S. faecium が $47.4 \%$ を占め, S. faecalis subsp. liquefaciens が $22.8 \%$, S. faecalis が $21.3 \%$ で, S. durans は 3.4\% であった。この同定成績を他の 6 項目 の生化学的性状試験により吟味したところ, “MSAG”試 験による S. faecalis および S. faecalis subsp. liquefaciens などの同定はかなり正確であるが，S. faecium の場合には若干正確性の劣ることが示唆された。

文献

1) Larkin, E.P., Litsky, W., Fuller, J.E.: Appl. Microbiol., 3, 98 (1955).

2) Larkin, E. P., Litsky, W., Fuller, J. E.: ibid., 3, 102 (1955).

3) Larkin, E. P., Litsky, W., Fuller, J. E.: ibid.,
3, 104 (1955).

4) Larkin, E.P., Litsky, W., Fuller, J.E.: Am. J. Pub. Health, 46, 464 (1956).

5) 堀江 進, 山形 誠, 井上広志, 和泉 力: 食衛 誌. 15, 110 (1974).

6) Kereluk, K.: Appl. Microbiol., 7, 324 (1959).

7) Raj, H., Wiebe, W.J., Liston, J.: ibid., 9, 295 (1961).

8) Difco Manual of Dehydrated Culture Media and Reagents, 9th ed. (1953).

9) Litsky, W., Mallmann, W.L., Fifield., C.W.: Am. J. Pub. Health, 43, 873 (1953).

10）堀江 進, 佐藤史郎, 森田 烹, 井上広志, 和泉 力, 山形 誠: 食衛誌. 15, 105 (1974).

11）厚生省監修：食品衛生検查指針一I p.93 (1973) 日本食品衛生協会.

12) Deibel, R.H., Lake, D.E., Niven, C.F.: J. Bacteriol., 86, 1275 (1963).

13) Barnes, E. M.: J. Gen. Microbiol., 14, 57 (1956).

14）橋本秀夫：メディヤサークル，No. 54，9 (1964). 